\title{
Qëndresa e popullsisë së trevave të Elbasanit ndaj agresionit serb të vitit 1913
}

\author{
Me rastin e 105 vjetorit
}

-ese-

Hyjni S.Ceka

Ka në historinë tonë, çaste të një rëndësie të veçantë... por, momentin më kulminant, në të gjitha përpjekjet e popullit shqiptar për liri kombëtare, e shënon Shpallja e Pavarësisë dhe ajo Ditë e Flamurit e 28 Nëntorit 1912.

Mbahet mend dhe është shkruar, nëpër faqet e historisë... se, më së pari, flamuri me shqiponjë dykrenore, u ngrit në Elbasan, më 25 Nëntor të vitit 1912. Mbi këtë datë simbolike, studiues dhe qytetarë atdhetarë, duhet t’i çojnë sytë herë e mbas here...

Akti i shpalosjes së Flamurit Kombëtar, ndër treva të Elbasanit, u shoqërua, në çast me ndërtimin e një administrate shqiptare, në rang prefekture, nëpër të gjitha hapësirat e qarkut... Duhet shënuar se, nën këtë juridiksion, atëherë ndodheshin edhe krahina të tilla, si: Mokra, Golloborda, Shëngjergji, Martaneshi, Zhullima, Malësia e Rrogozhinës dhe e Pezës, po ashtu dhe krejt Darsia e Hysgjokajt... gati dyfishi i kësaj prefekture që kemi sot. Kjo qeverisje lokale kishte për detyrë të zëvendësonte ish-administratën turke, në të gjitha instancat: prefekturë-nënprefekturë-krahinari...

Tërë kjo veprimtari përbënte një akt të ligjëruar për t'u rrëfyer forcave ndërluftuese të Koalicionit Ballkanik, krejt i pavarur nga Perandoria Osmane dhe... neutral e i papërzier në mosmarrëveshjet e palëve në konflikt. 


\section{Albanon}

Revistë kulturore

S’do mend që konstruktori i gjithë kësaj qeverisjeje lokale, ishte Aqif Pashë Biçakçiu, burrë shteti, nga më të mëdhenjtë që ka nxjerrë ndonjëherë vendi ynë... Prandaj atë s'e shohim në Vlorë, më 28 Nëntor 1912. Pozita kyçe që zinte Elbasani, në përballjen e agresionit, e kërkonte Aqif Pashën, ballë e përballë me armiqtë më të egër, në atë udhëkryq, ku ndërroheshin pushtuesit..., sepse nga një anë tërhiqej Armata Turke, në anë tjetër zbrisnin hordhitë e çetnikëve serbë.

Strategjia e Pashiqit, në këtë moment, ishte qartësuar e kishte dalë sheshit fare! Lakmitë agresive ishin shtazëruar... shpërtheu atavizma barbare. Bandat e Shumadisë kërkonin të krijonin Perandorinë e Stefan Dushanit... dhe patën yrysh të madh, rrëmbyer nga një delir i paparë gjakësimi... Marsho, ther me sfungji, derdh lumenj gjaku. Tmerro trojet shqiptare... më të katër anët.

Prandaj shqiptarët miratuan edhe ata strategjinë e tyre. Krahas zëvendësimit të administratës turke me qeverisjen shqiptare, do të bëhej dhe zënia e pozicioneve të Ushtrisë Osmane, nga forcat vullnetare vendëse...

... Hordhitë serbe, më 28 nëntor 1912, zbritën në Elbasan dhe qytetin e gjetën nën flamujt shqiptarë... pa asnjë këmbë osmanlliu... Ushtria turke vazhdonte tërheqjen nëpër baltërat e Muriqanit, e demoralizuar dhe e rraskapitur... Krejt! Paria e vendit ua bëri të qartë invadorëve të rinj: MOSPËRZIERJEN NË KONFLIKT DHE INDIPENDENCËN E SHPALLUR... Ky qëndrim as që u përfill nga ushtritë pushtuese...

Në prefekturën e Elbasanit, atëherë, u gjendën përballë dy pushtete: Administrata shqiptare dhe Komanda serbe. As edhe njëra palë s’i lëshoi pe tjetrës. Prefekti shqiptar mbante rendin e qeverisjen, në të gjitha instancat, duke pasur rreth nënprefektë e krahinorë... Aqif Pasha kishte në varësi zyrat e telegrafës, në të katër anët e qarkut, por edhe doganën (gjymrykun), financat, të ardhurat e monopolit, deri edhe gjykatat.

Serbët, me pretekst të ndjekjes së Armatës Turke, u përpoqën të përparonin në drejtim të perëndimit e të jugut. Po ngecën në Malasenjë e Shtërmen... Aty u përforcuan në "Hundë të Bregut", mbi Pazhok dhe mbajtën për vijë ndarëse vargun e kodrave Belik-Malasenjë-Shtërmen. Për tre muaj u gozhduan keq aty, pa mundur të kaptonin Zallin e Gostimës. E... të bënin sikur një hap, për Dumre, nëpër Qafë të Shalësit... Gjithë këto ndodhnin, sepse zona e Shpatit të Ulët kishte zbritur e gjitha në faqet e Shtëpanjit e të Gostimës, deri në pyjet e Gjyralës. Po kështu edhe Dumreja pat zënë Shalësin, Xibrakën dhe Kodrat e Cërrikut të Vjetër.

Duhet mbajtur mend se gjithë ky front popullor ishte ngritur në një zonë 
të pyllëzuar e të dendur... Atë kohë, nëpër Kodrat e Cërrikut, të Shalësit e të Xibrakës edhe zogjtë e kishin të vështirë të depërtonin, sepse vendi ishte shkozë e gjallë, përzier me ferrë e shkurre masive... Nëpër këta bunkerë natyrorë qe derdhur popullsia e krahinave të mbarë Elbasanit, fill mbas tërheqjes së ushtrive turke. Sigurisht që rezistenca kishte një qendër organizimi dhe, kuptohet që Aqif Pasha, dora vetë, ndodhej në krye të shtabit, por i pashfaqur, për të mos e ndërlikuar konfliktin me pushtuesin e ri serb.

Në këtë çast, zënë të dallohen udhëheqësit fshatarë, që sot i gjejmë të mbijetuar nëpër këngë. Dhe këta janë: Sulë Kurti i Shalësit, Dalip Tabaku i Pajovës, Osman Hana i Rrasës, Kamer Dyrmyshi i Vërçës... Pa përjashtuar prijës nga dyert e para të Shtëpanjit, Gostimës e Belëshit.

Ç’është e vërteta, “akademikët” tanë pak e kanë sjellë mendjen nga kjo anë e nëpër këto anë... Në Historinë e Shqipërisë nuk është shkruar, sikur një faqe, për qëndresën masive të fshatarësisë elbasanase, në periudhën marsprill 1913...

Po në ditët e sotme ka ndryshuar puna... Krejt! Një dokumentacion i pasur na është vënë në dispozicion, viteve të fundit. Hapja e Arkivit të Qeverisë së Ismail Qemalit dhe, kryesisht heqja e "karantinës" mbi fondin e Lef Nosit, përbëjnë një sihariq të veçantë për gjithë historinë, pa kahje politike. Veç kësaj, Bibliotekës Historike iu shtuan të plota "Brenga e Ballkanit" e Durhamit, "Memoarët" e Eqrem Bej Vlorës, vepra e Tucoviqit "Serbët dhe Shqiptarët"... Të përmendim pastaj edhe volumet me testamentet e Syrja Vlorës e Sejfi Vllamasit. Mbi të gjitha e të gjitha... lum që u hapëm!... I kemi mundësitë sot t'i sillemi qark e përqark botës... Të rrëmojmë rafte me dosje në Vjenë e në Londër, në Romë e në Paris...

... Kurrë njerëzimi s'e fali masakrën! Thellë atij viti, 1913-a shfryu me duf shpirtin serb të mizorisë. Gazetat e kohës përplot kanë qenë. Mbushur me bëmat e lukunive të Shumadisë... Nën dritën e gjithë këtij materiali, tashmë, gëzojmë të drejtën të pohojmë se konfrontimi shqiptaro-serb, i ngritur nëpër trevat e Elbasanit, gjatë muajve dhjetor 1912 e janar-shkurt-mars-prill 1913, ka qenë një organizim strategjik i përkryer... I pari mbas Shpalljes së Pavarësisë... Kjo nuk ndodhte në Elbasan, ashtu spontanisht.

Elbasani ishte vatra që kultivoi kapedanët atdhetarë që do të konstruktonin e do t'i prinin Ushtrisë sonë Kombëtare... Dhe këta s'qenë pak, por e tëra një plejadë, me kalorësin e famshëm, Kamo Sejdini në krye... pasuar nga Kasem Sejdini, i vëllai (komandant i Xhandarmërisë më vonë), Qamil 


\section{Albanon}

Revistë kulturore

Gëlqerexhiu-Elbasani (rektori i shkollës së parë shqipe për oficerë), Hasan Stafa (babai i Heroit të Popullit, Qemal Stafa), Abas Bej Taushani (dëshmori i monumenteve), Selaudin Blloshmi (shef i Shtatmadhorisë së Ushtrisë Mbretërore), Beqir Plangarica... e shumë e shumë të tjerë. Gjithë këta prijës ushtarakë, mbledhur rreth e rreth Aqif Pashës, punuan natë e ditë, në avanpostet e Vlorës për të mbajtur ushtrinë serbe të ngujuar brenda një territori fare të ngushtë... pa bërë as edhe një çap përtej harkut ShtëpanjëQafë e Shalësit-Valas Broshkë.

... Te mblidhej në Londër Konferenca e Ambasadorëve, në Serbinë e Karagjorgjeviçëve sa vinte e shtohej oreksi për ekspansion... Mafia e NAÇERTANIES dhe diplomacia e Pashiqit nxitnin për ofensivë hordhitë e tyre në Shqipëri... Qëllimi ishte të vinin nën okupim gjithë krahinat e Atdheut tonë... Të merrnin Dumrenë... Të dilnin brigjeve të Vjosës, të shkatërronin Qeverinë e sapolindur të Ismail Qemalit... Serbia kërkonte Shëngjin e Durrës e dalje në Adriatik, në brigje shqiptare... Kësaj do t’i arrihej me pushtimin e Myzeqesë të gjithë dhe gati të krejt Shqipërisë. Pas këtyre planeve fshiheshin pazare diplomatike, të projektuara... "Më jep, të jap. Lëshoj këtu e marr atje". S’kishte gjëkundi, nëpër botë, djallëzi më të rafinuar?! Në "hesapet” e veta pushtuesit serbë ishin të përpiktë dhe parashikues. Në të vërtetë Konferenca e Londrës atë drejtim do të merrte, nën diktatin e ARIUT RUS.

Në fund të shtatorit 1913, gjithë ushtria turke qe përqendruar në fshatin Seman të Fierit, në pritje për t'u imbarkuar e për t'u nisur për në Turqi. Kafshët e ngarkesës, tendat e qerret ushtarake u qenë shitur vendësve... Gjithë kjo masë njerëzish ishte gjysmë e armatosur, e paveshur, e pabukë, e paaftë për qëndresë.

Me kë priste të luftonte atëherë Ushtria Serbe, që bënte plan për beteja ofensive?! Sigurisht me popullsinë shqiptare! Njihej taktika e serbëve e luftërave me vendësit... Veç shkatërro e digj e ther me sfungji... Krijo varre të përbashkëta majë kodrash, për të përhapur panik e tmerr. Gjithë kjo mënyrë veprimi qe parë në Lumë e në Dibër, por edhe në Çermenikë, në fshatrat Prevallë e Neshtë.

Katundaria e Prefekturës së Elbasanit u tregua syçelë, e vetëdijshme dhe mprehu, gjer në shkallë të lartë, instrumentet e veta të alarmit. Turku na u hoq, vërtet qafe, por u këmbye me serbin që vinte më agresiv, më i lig, më dinak... Halldupi, kish ç'kish, e shprehte haptas... Ç’t’i bëje shqaut?! Të afrohej çlirimtar. E, veç kur ta ngulte sfungjinë... Mu në zemër! 
I erdhën vërdallë Shtërmenit... ta kishin për vete... Gjysma ortodoksë Shtërmeni!... Pat edhe Kishën e Shën Mërisë!... Në Pashkët e Qeshqekut bënë çmos të përziheshin me fshatarë, të festonin bashkë Krishtlindjet... Shtërmeni këshillohej me Lef Nosin... tregoi burrëri ky... hasmin s'e qasi përbrenda. U soll Kol Bodulli pastaj... që nga Elbasani... Gjëkundi se është shkruar për këtë biçim! Kola ishte karvanar që bënte rrugën e Manastirit. Andej shqehtë ia hodhën grepin dhe e futën në thes. E paguanin mirë. E mbajtën, e ruajtën, që ta përdornin kur t'u duhej.

Dhe ja!... Erdhi radha e Kolës! Shtërmenasit s’e lanë Kolën të përpjekë në katund. I vunë dajakun, më të parët... Dhe Kola ktheu majat, nga pat vënë thembrat... Shejtanllëku serb doli në dritë të diellit. Dasinë fetare hasmi desh ta përdorte si armë për qëllime të mbrapshta. Shpatarakët ortodoksë desh t’i vinte përpara si "kallauzë" kundër myslimanëve shqiptarë.

Si u mor vesh gjithë kjo, në Shtërmen zbriti legjendari Qorr Topuzi. Te shtëpitë e Kadijve u mblodhën burrat e dheut... Aty u lidh fjala... Të parët e Kuvendit, Jonus Topuzi e Met Kuqja, tokën duart, u rrokën në qafë, bënë besa-besë: Shpati është Shqipëri! S’ka farë lidhjeje me Serbi e me shqeh!

S'priste më puna! U ngrit Ushtria e Serbit kreshtave mbi Pazhok... U zgjuan këndej të mëdhenj e të vegjël dhe zunë shtigjet. Në ditët e fundit të shkurtit 1913, repartet e çetnikëve nisën të çanin nëpër Gostimë e nëpër Shtëpanjë. Sa me tërbim sulmuan, aq ashpër u pritën... Paçka se pushtuesit vinin me artileri e armatime të uzinave ruse e franceze dhe katundaria jonë qe armatosur veç me huta e martina.

Sos qenë veç Shtëpanji e Gostima aty?!.. Shpati i tërë! Shënavlash e Galigat... gjer Zavalina, matanë Bukanikut! Nga qe mbledhur gjithë ajo djalëri! Ku pat qenë ai vullkan që s'qe dukur gjer më atëhere?! Shpërtheu... Liri a vdekje! Ndryshe hasmi do të na zhdukte nga faqja e dheut. Qenë çelur muret e shtëpive... Mbushur me frëngji faqet e mureve. Mbinë tytat e dyfeqeve anekënd. Remat e ujit, kthyer në transhe. Mezhdat e arave u ngritën istikame. Breshëri krismash natë e ditë. Fronte betejash, Shtëpanji! Luftimet qenë të rrepta... fytafyt më në fund. Katundaria mbronte vatrën e saj... tokën e vet! E nuk lëshoi, sikur një pëllëmbë... Bota u çudit! Ata fshatarë, rritur me dhi e me dele, vunë përpara sërbët... I shfarosën deri në një në përleshjet te Shkalla e Shtëpanjit.

Pas gjithë kësaj pritej tërbimi i hakmarrjes. Me një gjakftohtësi të përsosur u organizuan, në çast, boshatisjet e fshatrave... Përtej Devolli, Bregu u 


\section{Albanon}

Revistë kulturore

ngrit... i gjithë. Erdhi në Shtëpanjë. Me karvane. Kafsharët bartnin pleq e fëmijë, orendi e plaçkë. Morën përpara edhe bagëtinë... Dërgo thellë pyjeve... ta ruanin andej. Lumi u shtrua në va mes Darzezës e Banjës. Kalonin muhaxhirë-trumbë. Plot halle mbi kurriz. Burrat bënë një tërheqje të rregullt, përpara trupave që erdhën dhe i përforcuan armiqtë. Aty mbetën të ngulur, në pozicione të reja.

Luftimet në Shkallë të Shtëpanjit janë treguar rëndom nga pleqtë, jo për gjë tjetër, por ngaqë kjo betejë shënon kacafytjen e parë shqiptaro-serbe në prefekturën tonë. E rëndësishmë qe se u shpëtua popullata nga kasaphana. Prijësit e atyre viteve qenë vërtet kapedanë, dinin ç'ishte "shpirti serb”. I druheshin egërsisë patologjike të shqehve... pangopësisë së tyre për gjak... Kishin jetuar luftërat në Kurshumlije, Toplicë e Nish, kur u zhdukën dhe u përpinë mijëra e mijëra shqiptarë... Kësaj iu ruajtën të urtët e shekujve! Malli e gjëja vete e vjen... po njeriu! Ai do ruajtur... Që të vazhdojë jeta e të grahë kombi...

Gjëma e luftës arriti në Gramsh.... Aty qe Gramshi... ngjit! Mbi grykat e Holtës. Kushtrimi mori dhé... Luginës së Devollit, në Lum të Vërçës e... përpjetë nëpër male. Në Koshnicë e në Lenie... Ç’e dini Gramshin, o vëllezër?! Ai krah, për aq sa ka pas jetë mbi tokë, nuk ka njohur pushtues e sundues. Keni marrë vesh se ç’kanë pas thënë sulltanët osmanllinj?!

Gramsh kaza,

Allah-bin-belasen!

Kaq patën thënë. Vunë nën thundër krejt njerëzimin, gramshakët i lanë në hall të tyre... Të gjente "belaja”, të përziheshe me ta! As bejlerë, as agallarë që njohu Gramshi. Mbi krye veç Zoti i Madh dhe i Vërtetë... Atij i faleshin, sa në Teqenë e Shëmbërdhenjit, në Teqenë e Dushkut... Dhe një shenjtor që predikonte në Fjalë të Perëndisë: Baba Meleqi i Shëmbërdhenjit...

Prijës kishin ngelur po të parët e fiseve. Gramshi i përveçëm!... Tokën sekush të vetën... kullotat-mushá! Vinin shqehtë tani... të bëheshin zotër në këto anë! Ç’ishte kjo farë, more?! ... Brofën gramshakët, zunë lugjet... Bregun e Holtës, grykave e grykave... Keni provuar t’i ngjiteni Holtës përpjetë?! Ç’e ka atë hije të rëndë?! Bjeshkë e gjallë e pirgje, me krye gjer në re! Aty u ngjit vija ndarëse midis ushtrisë pushtuese dhe forcave popullore. Që nga Strohëri e Kabashi, Cërujë, mbi përrua, Zgjypë, përtej Devolli.

Blegtorët "qibarë" gramshakë! Të merrnin gjak në vetull... Pyesnin ata për "vojnikë”?!... S’i futnin në hesap!... Fare! Në atë front të Holtës i shembën 
veç me shkëmbinj e gurë. I shuan. Me britmë e sokëllimë. Ik serbët, ndiq vërçenjtë... Krisma pastaj... tym “dynjaja”. Në kaq e kaq vite s’u ngrit një përmendore për gjithë ata kapedanë!.. Emrat e tyre nuk u skalitën në mermer të bardhë!... Gjëkundi!... Veç populli s’i harroi... I ruajti nëpër këngë... i përkëdheli me vargje... i heroizoi në balada... Mbas një shekulli kohë sot, na përmendin vallet luftarake, meloditë me fyej dhe elegjitë... Himne! Të gjitha për Kamberajn e Dyrmyshëve, për Ahmet Bajramin e Poroçanëve, për Xhelilt e Grabovës, për Musajt, Kullollët, për Ballinjtë.

Larg që këndej, thellë Serbisë, në Rashkë e Shumandi, pat ngelur një proverb: "XHEHNEM ME SY KANË PARË VEÇ ATA QË KALUAN SHQIPËRINË MË 1913, TË TJERËT KOT QË FLASIN...” Ndoshta falën e kanë për Holtën!..

Prita në jug, në Brigjet e Holtës u bë e padepërtueshme... Komanda serbe, në fillim të marsit 1913, provoi të çante nëpër Qafë të Shalësit, të shkelte Dumre e Darsi, të dilte patjetër në Myzeqenë e gjerë... Tashti agresionit i kundërvihej Dumreja... Fshatarësia jonë ndërmerrte një betejë në front të hapur. Synimi i vërtetë ishte mbrojtja e asaj hinke në Grykën e Shalësit, po krahët zgjateshin mjaft, se mbulohej krejt Gjyrala në Jug... E Cërriku, Valasi e Broshka në Veri. Në gjithë këtë ballë katundari qe derdhur mizëri. Nuk dallonin luftëtarët më! Burra ishin apo gra?! Djalëri a vajzëri?! Tërë Dumreja. Por edhe Darsia-thellë!

Të famshmit "çetnikë" që bridhnin përpara me flamurin e Shën Savës, u grinë nga plumbat e saçmat e fshatarëve patriotë. Si provuan të linin rrugën e karvaneve e të futeshin nëpër shtigje, armata serbe e pësoi edhe më keq. Ngeli ferrave e shkurreve. E mbyti balta e gjoli. Në Bllatën e Balashajve mbetën gjithë ç’tepruan. I përpiu lera atje... Lanë kockat për turp e për faqe të zezë...

Dështimi i mësymjes serbe në Qafë të Shalësit, në vargun e marrëzive të Karagjorgjeviçëve, shënonte veç katastrofë e demoralizim... Dhe "tërbimi" sllav ndizte pasione gjakësorësh në gjithë këtë hordhi egërsirash, me "kapica" në krye, me mjekra të palara. Pesë ditë e pesë net zgjatën luftimet në Qafë të Shalësit... Më të gjashtën serbët kthyen mendje. Zgjodhën shtegun sipër Broshkës. Duke përparuar me reparte të vogla, arritën në zemër të krahinës... Jo për t'u ndeshur më, po për të ndëshkuar, për t'u hakmarrë mizorisht, për të vrarë e për të therur, për të djegur e përcëlluar, siç kishin bërë gjer më ahere nëpër gjithë hapësirat shqiptare. 


\section{Albanon}

Revistë kulturore

Kjo taktikë e marrjes së krahëve dhe ky pushtim i kryeqendrës së krahinës, sidomos vënia dorë mbi "Kalanë e Gradishtës", i detyron forcat popullore të zënë pozicione të reja. Vija e konfrontimit kaloi rrëzë e rrëzë masiveve pyjore, të padepërtueshme, Xherije-Hardhi e Butë-Marinëz-Gjyralë.

Një barrikadë gjigande i qe ngritur gjithë atij karvani cubash e s'u ça më ai “istikam”. Invadorët s’i la të bëjnë përtej. Ngecën të shushatur e të shtazëruar. Të urryer nga vendësit, të harruar prej të vetëve. Qyqarë e mjeranë, nën heshtjen mortore të një fshati krejt të boshatisur, siç qe Belëshi i atyre ditëve.

Ç’e hidhëroi serbi atë mars! Pelin e bëri! Helm! Në vend që të kapnin parmendën, katundarët morën arratinë. Qe ndarë njerëzia... Ç’qenë për pushkë - në ballë të luftës. Të tjerët pyjeve: fshihu nga hasmi.

... Thënë të drejtën, angazhimi në luftime dobësoi syçeltësinë... U venit kujdesi për banorë... Luftëtarët bënin qëndresë nëpër shtigje dhe patën të fjetur mendjen për fëmijë e minorenë, për pleq e plaka. Kush i gjente ata?! Andej nga qenë futur!.. Kapedanët elbasanas, muaj me radhë, i mbajtën hapur sytë. Iu ruajtën masakrës e progromit... I mënjanuan ato në Shtëpanjë e në Holtë.

Në Belësh nuk ngjau kështu. Pyka e Broshkës - dalja e armikut në Gradishtë, solli hutim... Në vend që të kthenin për Belësh, forcat tona zunë pozicione të improvizuara... Strategjia e tërë e asaj lëvizjeje ishte: Armata Serbe të gozhdohej brendapërbrenda Elbasanit... Këmbë serbi të mos çapte përtej, që administrata e Vlorës të punonte normalisht!

Por jo! Serbi as që provoi të merrej me atë luftë frontale që ia kishin ngrehur shqiptarët. Kthyen nga instiktet barbare. Komanda organizoi gjuajtjen për adoleshentë... I gjeti ata buzë gjoleve, mes pyjeve, te kullotnin bagëtinë, në Gjelaurë e në Merhojë... në Parashkë e tek Tundë e xha Rrapit. Gjithë ç'qenë, i mblodhi bashkë te xhamia e fshatit. Pastaj i nisi. Atëhere ndodhi një masakër tragjike në Majë të Allajbegut... Një kasaphanë të vërtetë ngriti kanibalizmi serb në kuotën e tetëqindmetërshit, mbi kulm të Dumresë... Gjashtëdhjetë bij nënash u therën atë ditë të 7 marsit 1913. Të gjithë adoleshentë, si një dorë-një dorë, nga 14 deri 16 vjeç... Përrua u derdh gjak i ri shqiptar!

Dhe s'u shkrua më për ta... As u këndua... Qenë gonxhe e gonxhe... lule e lulëzim... i gjithë Dumresë. E prapë na thonë ta shtiem në harresë gjithë atë bolbë... Na nxisin të heshtim, me demek se erdhën të tjera kohë... dhe Serbinë me serbë do ta evropianizojnë. 
Por jo! U hesht një shekull plot për masakrat serbe, ndaj u lindën përbindësh që krijuan Mbrostarin e Srebenicën, Reçakun dhe Rahovecin dhe varret masive në Kosovë e gjetkë... Po të ishte shkruar, po të zinte vend në Historinë e Botës kanibalizmi i tërbuar serb, nuk do të kishim para syve veprën e shëmtuar të Sllobodan Milosheviçit. Pra, duhet të ishim marrë, kohë e më përpara, me nacionalizmin monstruoz të Naçertanies, që të mos kishim punë sot për Gjyqet e Hagës.

Ka dhe më... Ndodhi, ç'ndodhi, Dumreja s'u tund... Nuk çeli shteg... As për Vlashuk, as për Hysgjokaj. Serbët aq patën keq, sa plotësuan pasionet e tyre atavike. E lanë Belëshin... Lanë edhe belshakët, ngujuar pritave... I sfiduan, me një fjalë.... U organizuan pastaj. $U$ mblodhën qenë nga s'qenë. $U$ erdhën dhe përforcime, s'di nga ku. Po u bënë shumë. Përgatitjet filluan nën hundë të elbasanasve, te Kazermat e Shkumbinit. Dhe aty vazhduan për ditë me radhë.

Mos kujtoni se kaloi pa u vënë re gjithë kjo lëvizje. Vlonte Elbasani. E natën s'bënte gjumë. Në sarajet e Biçakçinjve mblidheshin kapedanët e bisedonin kokë më kokë. Të parët e fiseve po aty. Një palë hynin, një palë dilnin. Aqif Pasha, menduar, merrte e jepte, po mes të urtëve.

... Serbët mësynë nga Derveni kësaj here. Nëpër rrugë kryesore, Luginës së Shkumbinit, mespërmes Shqipërisë. U nisën me salltanete... sigurisht, me artileri, fjalë e fundit e teknikës... me tambure e bori përpara... E tundën. Po ranë në demonet e Bonatëve. Peqini në kohë të vet, një pasha ka patur, po qe pasha me halle. Për kërrkënd se i bënte veshi tërr. Turgutin, që thonë, veç ai e pat bërë zap. Demir Pasha me peqinas... Ku pyetnin për serbër peqinasit?! S’i kishin për gjë fare! Nga numërohej Elbasan atyre viteve, ka qenë veç burrëri e shqiptari.

Me t’u hapur fjala se hasmi bëri ballë, brofi njerëzia... Aty mbinë, mbi Grykë të Dervenit, në Bishqem. Alush Aga me rrogozhinas. Myselimi i gjithë me Din Dervishin në krye. Pajova e Dalip Tabakut. Zhullimë e Krrabë nën bajrakun e Sulë Selimes. E tërë gryka e Paprit... E kodrat e Darsisë. Fytafyt me serbët... Ata bjer e këta bjer. Ç’i dini shqiptarët, more të humburit e shpellave e të brrajkave?! Ç’keni që na bini më qafë kot së koti?! Shkurreve mbetën topa e mitralozë dhe teknikë e fjalës së fundit. Borizanë e tamburistë e vojnikë të mjerë qelbën kanalet e Bishqemit. Shkumbini erdhi trap më trap. Valë e lumit i mori me vete dhe i vuri përpara. Krejt! ... Me flamuj të lavdishëm... Me ikona të shenjta të Cvjatij Savës... E gjithë ato kapica, ngelur pa krena... 


\section{Albanon}

Revistë kulturore

U bënë njëqind vjet... Në Elbasan nuk doli, sikur një studiues, të bëhej burrë. Gjithë atë qëndresë të viteve 1912-1913 ta fuste në histori. Ta ruante ndër thesare. Se është vlerë e vyer e trevave tona. E lanë të vejë kot. Të harrohet. E, në pyetshi këtë brezin e sotëm, kurrkush nuk e di ta thotë një fjalë për ato beteja. Kurrkujt se i përmendet ai gjak, derdhur lumë, në Prevallë e në Neshtë, në Allajbeg e në Darsi. Merremi me sensasione... me firmëtarë, ngelur cepave nëpër deklarata. Flakim tej një varg përpjekjesh... Beteja në Shtëpanjë e në Holtë, në Qafë të Shalësit e Derven të Bishqemit.

Ajo Pavarësi më 25 nëntor 1912 ndaj u shpall... tri ditë përpara Vlorës. Po tri ditë për t'u prerë hovin hordhive serbe... Dhe, me të vërtetë, u bëri ballë. Pengoi gjithë atë "yrysh"... Se me atë vrull dhe egërsi do ta kishin përpirë Shqipërinë me ç'kishte e ku kishte.

Harrojmë vullkanin. Po qenë gjashtë muaj ato ditë. Periudhë e veçantë në histori në të katër anët Elbasan, nga ishte, luftoi si asnjëherë tjetër.... Derdhi gjak për të ngritur themelet e shtetit shqiptar. Me cinizëm armiqtë shpotitin se Pavarësinë e kemi dhuratë nga diplomacia e Vjenës. Ne... Jo! Çdo gjë e kemi nga duart tona.

Mes gjithë shqiptarëve, sot elbasanasit ndihen kryelartë. Po, me Shtëpanjën e Holtën veç; me Shalësin e Dervenin; me Allajbeg e Neshtë e Prevallë... Kur nuk ngritën, sikur një përmendore, për gjithë ata bij nënash.

...Lule e lulëzim i gjithë Elbasanit! 